\title{
Improvement of Cognitive Deficit in Alzheimer's Disease Patients by Long Term Treatment with Korean Red Ginseng
}

\author{
Jae-Hyeok Heo ${ }^{1}$, Soon-Tae Lee ${ }^{2,3}$, Min Jung Oh ${ }^{2,3}$, Hyun-Jung Park ${ }^{2,3}$, Ji-Young Shim ${ }^{2,3}$, Kon Chu $^{2,3}$, \\ and Manho Kim ${ }^{2,3^{*}}$ \\ ${ }^{1}$ Department of Neurology, Seoul Medical Center, Seoul 131-130, Korea \\ ${ }^{2}$ Department of Neurology, Seoul National University Hospital, Seoul 110-744, Korea \\ ${ }^{3}$ Program in Neuroscience, Neuroscience Research Institute of SNUMRC, Seoul National University, Seoul 110-744, Korea
}

A 24-week randomized open-label study with Korean red ginseng (KRG) showed cognitive benefits in patients with Alzheimer's disease. To further determine long-term effect of KRG, the subjects were recruited to be followed up to $2 \mathrm{yr}$. Cognitive function was evaluated every 12 wk using the Alzheimer's Disease Assessment Scale (ADAS) and the Korean version of the Mini Mental Status Examination (K-MMSE) with the maintaining dose of $4.5 \mathrm{~g}$ or $9.0 \mathrm{~g} \mathrm{KRG}$ per d. At $24 \mathrm{wk}$, there had been a significant improvement in KRG-treated groups. In the long-term evaluation of the efficacy of KRG after 24 wk, the improved MMSE score remained without significant decline at the 48th and 96th wk. ADAS-cog showed similar findings. Maximum improvement was found around week 24. In conclusion, the effect of KRG on cognitive functions was sustained for $2 \mathrm{yr}$ follow-up, indicating feasible efficacies of long-term follow-up for Alzheimer's disease.

Keywords: Panax ginseng, Korean red ginseng, Alzheimer disease, Long term effect

\section{INTRODUCTION}

In the recent decade, the prevalence of dementia increased as the proportion of elderly population was expanding. The number of subjects with dementia has been doubling every $20 \mathrm{yr}$ and will reach 81.1 million by 2040 [1]. In spite of enormous research efforts, only a few symptomatic treatment options currently exist. Anticholinesterases and N-methyl-D-aspartate (NMDA) receptor blockers are clinically in use as anti-dementia medications, but they cannot prevent the disease cascade, and provide modest symptomatic benefits. Moreover, the active Amyloid beta immunization treatment for Alzheimer's disease (AD), which had been suggested to modify the disease process, was halted due to critical adverse events [2]. Clinical trials with herbal medicines

(c) This is an Open Access article distributed under the terms of the Creative Commons Attribution Non-Commercial License (http://creativecommons.org/licenses/by-nc/3.0/) which permits unrestricted non-commercial use, distribution, and reproduction in any medium, provided the original work is properly cited. have been actively investigated, warranting discovery of new drug [3]. Ginseng is one of the most popular herbal medicines used, and has been proven to have effects on cognitive functions, such as attention, working memory performance, processing and auditory reaction time in healthy individuals $[4,5]$.

However, only a few studies have shown effects of ginseng on dementia [6,7]. These studies investigated the effects of total powder extract of Panax ginseng or Korean red ginseng $(\mathrm{KRG})$ in patients with $\mathrm{AD}$, followedup for either three or six mo. Although neuropsychological assessment with the Alzheimer's Disease Assessment Scale (ADAS) or the Korean version of the Mini-Mental Status Examination (K-MMSE) showed cognitive im-

Received 05 Jul. 2011, Revised 12 Oct. 2011, Accepted 13 Oct. 2011

*Corresponding author

E-mail: kimmanho@snu.ac.kr

Tel: +82-2-2072-2193, Fax: +82-2-3672-7553 
provements, whether the effect of ginseng was transient or not remained unknown, due to limitation of study duration.

In this study, we attempted to test the long-term efficacy of ginseng by extending follow-up duration. The goals of this study were: 1) to further clarify the longterm efficacy of KRG as an adjuvant therapy to conventional anti-dementia medications in patients with $\mathrm{AD}$ and 2) to monitor the cognitive changes during the extended follow-up duration.

\section{MATERIALS AND METHODS}

\section{Patients}

The patients were included according to previously described inclusion and exclusion criteria [7]. The inclusion criteria were, as follows: 1) probable AD consistent with the criteria of the National Institute of Neurologic and Communicative Disorders and Stroke-Alzheimer's Disease and Related Disorders Association [8], 2) older than $50 \mathrm{yr}$, and 3) baseline Mini-Mental State Examination score of $\geq 10$ and $\leq 26$. Participants treated with conventional anti-dementia medication were allowed at least for 6 mo before the study. The exclusion criteria were: 1) history of psychiatric disorder, seizure disorder, or medical condition that would limit the completeness of the study, and 2) cognitive impairment due to stroke, hypoxic brain damage, cerebral neoplasia, infection, and medications, such as antidepressants or psychoactive drugs. Sixty-one patients, aged 50 to $80 \mathrm{yr}$, had been enrolled. Informed consent to participation in this study was obtained from all subjects and the study was approved by the Institutional Review Board of Seoul National University Hospital.

\section{Korean red ginseng treatment}

The patients had been grouped according to the doses of KRG, as previously described [7]. In brief, using a 1:1:2 randomization ratio, the patients were allocated in three treatment groups: low-dose KRG (4.5 g/d), highdose KRG (9 g/d), and control. KRG (total powder capsule, 6-year-old root; Korea Ginseng Corporation, Daejeon, Korea) was administered in a divided dose twice or three times a day. Ginsenosides, the active constituent of $\mathrm{KRG}$, are composed of $\mathrm{Rb}_{1}(1.96 \%), \mathrm{Rb}_{2}(2.18 \%)$, Rc (1.47\%), Rd (0.72\%), Re (1.11\%), Rf (0.24\%), Rg $(0.49 \%), \operatorname{Rg}_{2}(0.13 \%), \operatorname{Rg}_{3}(0.12 \%), \mathrm{Rh}_{1}(0.12 \%)$, and $\mathrm{Rh}_{2}(0.003 \%)$, and account for $8.54 \%$ of the herb [9]. Conventional anti-dementia medications (acetylcholinesterase inhibitors, i.e., donepezil, galantamine, and rivastigmine) were continued during the study period. For the initial $24 \mathrm{wk}$, there were 15 subjects in the lowdose KRG group and 15 subjects in the high-dose KRG group. The control group consisted of 31 patients who did not receive KRG and were compared to those in the KRG groups.

After $24 \mathrm{wk}$, the same doses and formula KRG powder capsules were provided continuously to the patients in the KRG groups for $2 \mathrm{yr}$. In this extended period, we continued the study with the KRG groups, but not with the control group.

\section{Neuropsychological assessments}

A neurologist or a supervised technician administered the neuropsychological tests. Neuropsychological assessments included the ADAS-cognitive subscale (ADAS$\operatorname{cog}$ ) and ADAS-non-cognitive subscale (ADAS-noncog), the K-MMSE and Clinical Dementia Rating (CDR) scale. The tests were performed before taking the $\mathrm{KRG}$, and at 12 and $24 \mathrm{wk}$ after KRG administration. In the KRG groups, neuropsychological evaluation for the long-term follow up (i.e., between $24 \mathrm{wk}$ and $2 \mathrm{yr}$ ) was performed at $12 \mathrm{wk}$ intervals.

\section{Statistical analysis}

We compared the results of neuropsychological tests between KRG groups and the control group using the SPSS ver. 11.5 (SPSS Inc., Chicago, IL, USA). The data are expressed as means \pm SD or as numbers. Inter-group comparisons of changes in ADAS and MMSE score were performed using the Student's t-test, and the frequencies of side effects and withdrawal from the study were compared using Fisher's exact test. All $p$-values are two-tailed, and statistical significance was accepted for $p$-values $<0.05$. The neuropsychological scores from the extended follow-up period ( $24 \mathrm{wk}$ to $2 \mathrm{yr}$ ) of the KRG groups were compared to baseline scores.

\section{RESULTS}

There were no differences in baseline characteristics between the groups, including age $(p=0.804)$, gender $(p=0.390)$, ADAS-cog $(p=0.561)$, ADAS-noncog $(p=0.060), \operatorname{MMSE}(p=0.925)$, and CDR $(p=0.450)$ scores, as well as in composition of conventional antidementia drugs $(p=0.308)$ (Table 1$)$. The performance on the ADAS-cog showed significant difference between the high-dose KRG and control. At 12 wk, the mean changes in the high-dose KRG and control groups were $-4.0 \pm 12.3$ and $-0.4 \pm 5.9$, respectively, and at $24 \mathrm{wk}$ the 
Table 1. Baseline characteristics of the Alzheimer's disease patients

\begin{tabular}{lcccc}
\hline & & Korean red ginseng & \multicolumn{2}{c}{ Control } \\
\cline { 2 - 4 } No. & $4.5 \mathrm{~g}$ & $9 \mathrm{~g}$ & Total & 31 \\
M:F ratio & 15 & 15 & 30 & $10: 21$ \\
Age & $6: 9$ & $8: 7$ & 67.16 & $66.7(7.5)$ \\
ADAS & $66.1(6.7)$ & $27.1(9.4)$ & $25.9(9.5)$ & $27.3(12.6)$ \\
-cog & $23.6(8.4)$ & $23.0(8.7)$ & $21.3(7.8)$ & $20.5(9.1)$ \\
-noncog & $19.7(6.8)$ & $4.1(3.3)$ & $4.0(2.9)$ & $6.7(5.1)$ \\
K-MMSE & $3.9(2.6)$ & $21.4(6.6)$ & $21.8(5.3)$ & $21.5(4.4)$ \\
CDR & $22.1(4.0)$ & $1.4(1.1)$ & $1.2(0.9)$ & $1.1(0.3)$ \\
\hline
\end{tabular}

Values are given as mean (SD) scores.

ADAS, Alzheimer's Disease Assessment Scale; ADAS-cog, ADAS-cognitive subscale; ADAS-noncog, ADAS-non-cognitive subscale; K-MMSE, Korean version of the Mini-Mental Status Examination; CDR, Clinical Dementia Rating.

changes were $-13.8 \pm 7.4$ and $-1.2 \pm 6.0$, respectively. The group taking $4.5 \mathrm{~g}$ of KRG showed no significant dif-

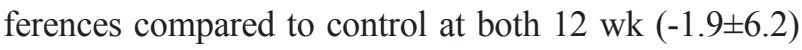
and $24 \mathrm{wk}(-4.9 \pm 5.0)$ (Fig. 1A). Similarly, there was a significant difference in the K-MMSE scores in the KRG group ( $4.5 \mathrm{~g} / \mathrm{d}$ plus $9 \mathrm{~g} / \mathrm{d}$ ) compared to control at both 12 wk (1.4 $\pm 3.4 v s .-0.5 \pm 2.9)$ and $24 \mathrm{wk}(2.8 \pm 3.4 v s .0 .3 \pm 2.9)$ (Fig. 1B). However, the differences in K-MMSE scores between each KRG group and control were not significant at both follow-ups. In ADAS-non-cog score, KRG failed to show any statistical significance. No significant difference in adverse events was found between the treatment and control groups $(p=0.853)$. Five patients in the low-dose KRG group, six patients in the high-dose KRG group, and twelve patients in the control group reported adverse effects and withdrew from the study during the first 24 wk. Participants reported mild symptoms of heat sensation, nausea, diarrhea, and headache, and all subjects who reported adverse events withdrew from the study.

In the long-term evaluation of the efficacy of $\mathrm{KRG}$ after $24 \mathrm{wk}$, the ADAS-cog and MMSE scores sustained without apparent declining at each visit for $2 \mathrm{yr}$ (Fig. $2 \mathrm{~A}, \mathrm{~B})$. In the low-dose group, the initial MMSE was $22.0 \pm 4.0$, at the 48 th wk was $25.7 \pm 3.0$, and $23.7 \pm 4.8$ at the 96th wk. In the high-dose group, the initial MMSE was $21.4 \pm 6.6,22.0 \pm 5.7$ at the $48 \mathrm{th}$ wk, and $24.0 \pm 3.7$ at the 96th wk, showing slight improvement or similar to the initial status. There was no tendency to decline. ADAS-cog showed similar findings of improvement from $19.7 \pm 6.8$ (initial) to $9.5 \pm 6.3$ (96th wk) in $4.5 \mathrm{~g}$ group, and from $23.0 \pm 8.7$ (initial) to $12.8 \pm 6.8$ (96th wk) in $9.0 \mathrm{~g}$ group. In this study, maximum improvement was found around $24 \mathrm{wk}$; however, there was no definite
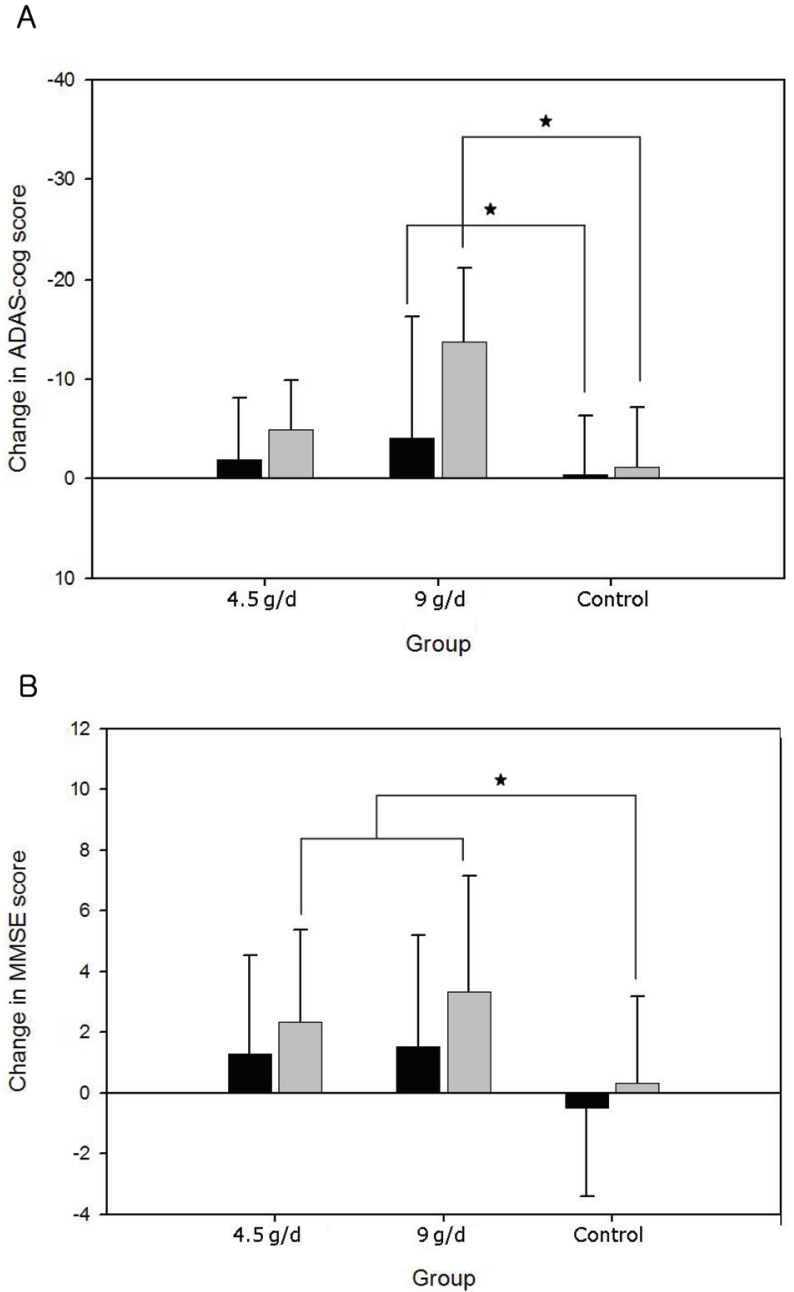

Fig. 1. Changes in neuropsychological tests over 24 wk. Korean red ginseng improved Alzheimer's Disease Assessment Scale-cognitive subscale (ADAS-cog) (A) in the high-dose ginseng group, compared with control, at both 12-week and 24-week follow-up evaluations. Korean version of the Mini-Mental Status Examination (K-MMSE) score was also improved at 24-week follow up in the ginseng group, compared to control (B). Black bar, 12 wk; grey bar, 24 wk. ${ }^{*} p<0.05$ compared to control, independent $t$-test. 
A

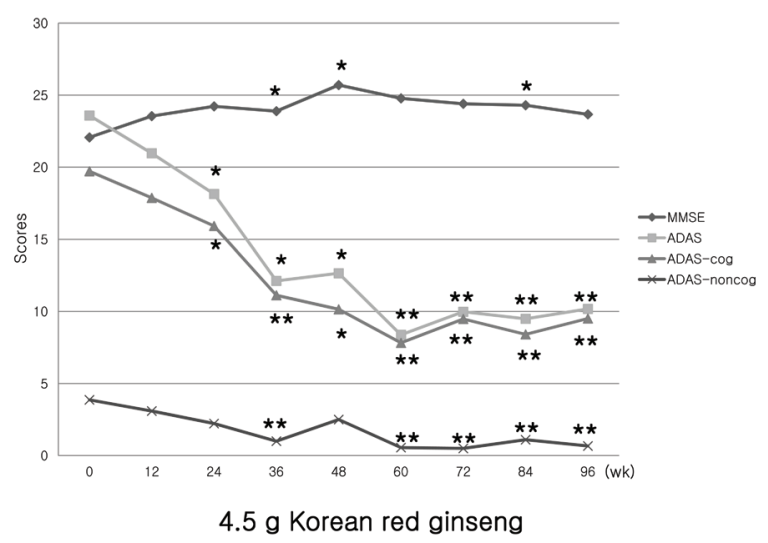

B

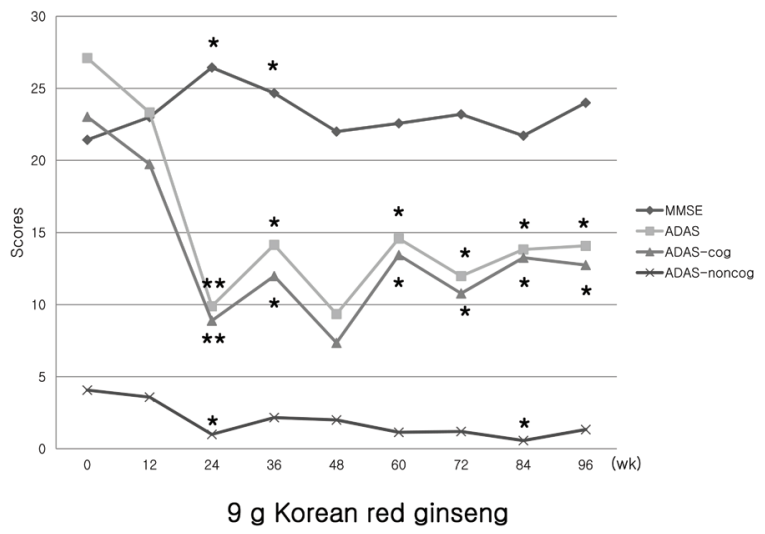

Fig. 2. The mean scores of Alzheimer's Disease Assessment Scale (ADAS), ADAS-cognitive subscale (ADAS-cog), ADAS-non-cognitive subscale (ADAS-noncog), and Korean version of the Mini-Mental Status Examination (K-MMSE) in the Korean red ginseng group (A, $4.5 \mathrm{~g} / \mathrm{d}$ group; B, $9 \mathrm{~g} / \mathrm{d}$ group) at each followed time for $2 \mathrm{yr}$ (96 wk). ${ }^{*} p<0.05$ compared to baseline, ${ }^{* *} p<0.01$ compared to baseline, paired t-test.

evidence of declining course thereafter. Taken together, the cognitive performance measured at 2-year follow-up visit was not different from initial evaluation.

\section{DISCUSSION}

The purpose of this study was to determine the efficacy of KRG with the extended period up to 2 yr. Based on the previous 12-week randomized open-label study with KRG, maintaining of KRG did not show declining of scores measured by ADAS-cog and K-MMSE after this period. Therefore, the effect of KRG on cognitive functions can be sustained at least for $2 \mathrm{yr}$, suggesting feasible long-term efficacy for AD.

Due to the explosive growth of the aged population, there's a growing concern for dementia, particularly AD, an aging-related major degenerative disorder. Because it's becoming an issue for the whole society, there have been many clinical trials to develop drugs to arrest the progressive cognitive decline of the dementia patients. Approved acetylcholinesterase inhibitors, such as donepezil, galantamine or rivastigmine, have been tested for their efficacy at least for 6 mo and for up to $5 \mathrm{yr}$. However, since these drugs are targeted for the reduced acetylcholine due to cholinergic neuronal loss, none of them can protect the degenerative process of $\mathrm{AD}[10,11]$. In this study, we found KRG-related improvements in cognitive function and sustainability of the clinical efficacy in patients with AD. Previously, data on long-term outcomes of KRG in AD patients are limited, not exceeding several months [6,7]. Therefore, these studies were unable to determine whether the effect of ginseng was only temporary or could last with inhibiting the progressive course of AD. Our findings show that the efficacy of $\mathrm{KRG}$ on cognitive function in $\mathrm{AD}$ can be maintained for at least $2 \mathrm{yr}$.

In acetylcholinesterase inhibitors, several long-term (over 2 yr) extension trials have demonstrated that, although the efficacy of medications was apparent, they could not block or reverse the cognitive decline [10,11]. The decline in the MMSE score over $2 \mathrm{yr}$ was usually 2.5 to 4.0 points, compared to initial evaluation $[12,13]$. In patients taking conventional medication, the usual pattern of cognitive decline shows initial improvement for 3 or 6 mo and then decrease to the initial level at around $1 \mathrm{yr}$. Then, they progressed thereafter. In contrast, in our study, the ADAS-cog and K-MMSE scores have been sustained without apparent declining at each visit time for $2 \mathrm{yr}$. This clinical course may be attributed to the difference of underlying mechanisms in ginseng from anticholinesterase.

The effects of ginseng on the cognitive function with underlying mechanisms have been proposed $[5,14,15]$. Ginsenoside $\mathrm{Rb}_{1}$ is known to improve learning and memory in hippocampus-dependent tasks and increased cell survival in the dentate gyrus and hippocampal subregion $\mathrm{CA} 3$ [14]. Ginsenoside $\mathrm{Rb}_{1}$ attenuated $\mathrm{A} \beta_{1-42}$-induced neurotoxicity and tau hyperphosphorylation at multiple AD-related sites in a dose-dependent manner [15]. In addition, it has been suggested that ginsenoside $\mathrm{Rg}_{1}$ and $\mathrm{Rb}_{1}$ potentiated the cholinergic pathways in the central nervous system. Thus, both $\mathrm{Rg}_{1}$ and $\mathrm{Rb}_{1}$ enhanced choline acetyltransferase activity and inhibited acetylcholine -esterase activity, thereby enhancing the function of cholinergic system [16]. Administration of $\mathrm{Rg}_{1}$ and $\mathrm{Rb}_{1}$ in weaning mice increased the cortex thickness and density of synapses in the hippocampal CA3 region, which 
is suggested to modulate synaptic plasticity, regarded as one of the most essential mechanism in learning and memory [17].

Our study was limited because no placebo was used in the control group and we could not prove whether KRG is a cognitive enhancer like acetylcholinesterase inhibitors or disease-modifying drugs. Additional biomarker study is required to clarify this. Nevertheless, our results suggest that KRG treatment is both safe and feasible, and is effective for the long-term management of $\mathrm{AD}$ patients.

\section{ACKNOWLEDGEMENTS}

This work was supported by the grants from the Korean Society of Ginseng 2009 and 2010, funded by Korea Ginseng Corporation.

\section{REFERENCES}

1. Ferri CP, Prince M, Brayne C, Brodaty H, Fratiglioni L, Ganguli M, Hall K, Hasegawa K, Hendrie H, Huang Y et al. Global prevalence of dementia: a Delphi consensus study. Lancet 2005;366:2112-2117.

2 . Wisniewski T. Is amyloid- $\beta$-peptide immunization clinically effective in patients with Alzheimer's disease? Nat Clin Pract Neurol 2005;1:84-85.

3. Akhondzadeh S, Abbasi SH. Herbal medicine in the treatment of Alzheimer's disease. Am J Alzheimers Dis Other Demen 2006;21:113-118.

4. Sorensen H, Sonne J. A double-masked study of the effects of ginseng on cognitive functions. Curr Ther Res 1996;57:959-968.

5. Scholey A, Ossoukhova A, Owen L, Ibarra A, Pipingas A, He K, Roller M, Stough C. Effects of American ginseng (Panax quinquefolius) on neurocognitive function: an acute, randomised, double-blind, placebocontrolled, crossover study. Psychopharmacology (Berl) 2010;212:345-356.

6. Lee ST, Chu K, Sim JY, Heo JH, Kim M. Panax ginseng enhances cognitive performance in Alzheimer disease. Alzheimer Dis Assoc Disord 2008;22:222-226.

7. Heo JH, Lee ST, Chu K, Oh MJ, Park HJ, Shim JY, Kim M. An open-label trial of Korean red ginseng as an adjuvant treatment for cognitive impairment in patients with Alzheimer's disease. Eur J Neurol 2008; 15:865-868.
8. McKhann G, Drachman D, Folstein M, Katzman R, Price D, Stadlan EM. Clinical diagnosis of Alzheimer's disease: report of the NINCDS-ADRDA Work Group under the auspices of Department of Health and Human Services Task Force on Alzheimer's Disease. Neurology 1984;34:939-944.

9. Nam KY. The comparative understanding between red ginseng and white ginsengs, processed ginsengs (Panax ginseng C.A. Meyer). J Ginseng Res 2005;29:1-18.

10. Burns A, Gauthier S, Perdomo C. Efficacy and safety of donepezil over 3 years: an open-label, multicentre study in patients with Alzheimer's disease. Int J Geriatr Psychiatry 2007;22:806-812.

11. Minthon L, Wallin AK, Eriksson S, Wattmo C, Andreasen $\mathrm{N}$. Long-term rivastigmine treatment in a routine clinical setting. Acta Neurol Scand 2009;119:180-185.

12. Courtney C, Farrell D, Gray R, Hills R, Lynch L, Sellwood E, Edwards S, Hardyman W, Raftery J, Crome P et al. Long-term donepezil treatment in 565 patients with Alzheimer's disease (AD2000): randomised double-blind trial. Lancet 2004;363:2105-2115.

13. Kanaya K, Abe S, Sakai M, Fujii H, Iwamoto T. Changes in cognitive functions of patients with dementia of the Alzheimer type following long-term administration of donepezil hydrochloride: relating to changes attributable to differences in apolipoprotein E phenotype. Geriatr Gerontol Int 2010;10:25-31.

14. Liu L, Hoang-Gia T, Wu H, Lee MR, Gu L, Wang C, Yun BS, Wang Q, Ye S, Sung CK. Ginsenoside $\mathrm{Rb}_{1}$ improves spatial learning and memory by regulation of cell genesis in the hippocampal subregions of rats. Brain Res 2011;1382:147-154.

15. Zhao R, Zhang Z, Song Y, Wang D, Qi J, Wen S. Implication of phosphatidylinositol-3 kinase/Akt/glycogen synthase kinase- $3 \beta$ pathway in ginsenoside $\mathrm{Rb}_{1}$ 's attenuation of beta-amyloid-induced neurotoxicity and tau phosphorylation. J Ethnopharmacol 2011;133:1109-1116.

16. Zhang JT, Liu Y, Qu ZW, Zhang XL, Xiao HL. Influence of ginsenoside $\mathrm{Rb}_{1}$ and $\mathrm{Rg}_{1}$ on some central neurotransmitter receptors and protein biosynthesis in the mouse brain. Yao Xue Xue Bao 1988;23:12-16.

17. Ying Y, Zhang JT, Shi CZ, Qu ZW, Liu Y. Study on the nootropic mechanism of ginsenoside $\mathrm{Rb}_{1}$ and $\mathrm{Rg}_{1}$ : influence on mouse brain development. Yao Xue Xue Bao 1994;29:241-245. 